\title{
EI Yazısını Dijital Metne Çeviren Mobil Uygulama
}

\author{
Mehmet Oytun SARIFAKIOĞLU ve *Özgün YILMAZ \\ Ege Üniversitesi, Bilgisayar Mühendisliği Bölümü, İzmir, Türkiye
}

\section{Özet}

Bu çalışmada el yazısını dijital yazıya dönüştüren bir mobil uygulama anlatılmaktadır. Kullanıcıların akıllı telefonlarını kullanarak el yazısı ile aldıkları notları dijital ortama kolaylıkla aktarmaları amaçlanmaktadır. Bu uygulama bir yazı görüntüsünü akıllı telefonun galerisinden veya kamera aracılı̆̆ 1 ile girdi olarak almaktadır. Uygulama istemci sunucu mimarisinde tasarlanmıştır ve uygulama arayüzünde seçilmiş olan fotoğraf, sunucuda bulunan bir derin öğrenme modeli aracılığıyla dijital metne çevrilmekte ve sonuçlar istemciye (mobil uygulamaya) gönderilmektedir. Sunucu tarafı Python programlama dili ve Flask çerçevesi ile geliştirilmiştir. Mobil uygulama, Dart programlama dili ile Flutter platformunda gerçekleştirilmiştir. Bu sayede iOS ve Android platformlarını desteklemektedir ve daha fazla kullanıcının bu uygulamaya erişebilmesi sağlanmıştır. Bu uygulama ile yazılı kaynaklar hızlı ve etkin bir şekilde dijital ortama aktarılabilir.

Anahtar kelimeler: El yazısı tanıma, derin öğrenme, insan bilgisayar etkileşimi, mobil uygulama

\section{A Mobile Application for Handwritten Text Recognition}

\begin{abstract}
In this paper, a mobile application that converts handwriting to digital text is described. The aim is that users can easily transfer handwritten notes to digital media using their smart phones. This application takes a text image as input from the smartphone's gallery or via the camera. The application is designed in client server architecture and the photo selected in the application interface is converted into digital text via a deep learning model on the server and the results are sent back to the client (mobile application). The server-side was developed using Python programming language and the Flask framework. The mobile application was developed using Flutter framework and Dart programming language. Thus, it supports iOS and Android platforms and more users can use this application. By using this application, written sources can be transferred to digital text quickly and effectively.
\end{abstract}

Key words: Handwriting recognition, deep learning, human computer interaction, mobile application

\section{Giriş}

Günümüzde gelişen teknoloji ile birlikte defter ve kağıtlarda bulunan el yazısı kaynakları fonksiyonelliğini yavaş yavaş kaybetmeye başlamıştır. İnsanlar araştırmalarında daha çok dijital ortamları (internet, bilgisayar, akıllı telefon vb.) tercih etmeye başlamıştır [1]. Fakat zaman ve hız anlamında kazanç sağlanılması için kağıtlardan, defterlerden ve kitaplardan dijital ortama geçiş için pratik yollar geliştirilmelidir. Geçmişten günümüze kadar gelmiş olan sayısız basılmış ve el yazısı kaynaklar (ansiklopediler, elyazması notlar, kişilerin kendi defterleri, vb.) dijital ortama geçiş sürecinde fazla zaman harcanmasına sebep olabilmektedir.

*Sorumlu yazar: Özgün YILMAZ Adres: Ege Üniversitesi, Bilgisayar Mühendisliği Bölümü, İzmir, TÜRKIYE. E-mail adresi: ozgun.yilmaz@ege.edu.tr, Tel: +90 2323115319 
Bu dijital geçiş sürecine ihtiyaç duyulan tek alan araştırma platformları değildir. Günlük yaşamda, iş hayatında, kamusal alanda gerçekleşen işlemlerde kağıtta bulunan yazıların dijital ortama geçirilmesi günümüzde söz konusudur [2]. İnsanlar mesleklerinde gerektiği kadar verimli olabilmek için sürekli bir çalışma ve öğrenme süreci içindedirler. Günümüzde bunun gibi süreçlerin içerisinde olan insanlar ayrıca yazıların gerekli platformlarda da bulunabilmesi için ekstra olarak bir zaman ve iş gücü harcamaktadırlar. Bu sürecin zaman ve iş yükü anlamında mümkün olduğunca hafifletilmesi iş hayatına mutlak bir verim ve etkinlik kazancı sağlayacaktır.

$\mathrm{Bu}$ çalışmada görüntü işleme ve derin öğrenme tabanlı bir mobil uygulama ve sunucu tarafı anlatılmaktadır. Bu uygulamada kullanıcı bir sunucuya mobil uygulama ile bir istek iletmektedir. $\mathrm{Bu}$ istek bir yazı görüntüsüdür. Kullanıcı isteğine bağlı olarak galeriden bir fotoğraf seçebilir veya akıllı telefonun kamerasına erişerek kendisi fotoğraf çekerek görüntü elde edebilir. Bu isteği mobil uygulama arayüzünde bulunan buton ile gerçekleştirmektedir. İletilen istek, sunucuda bulunan bir derin öğrenme modeline ulaşmaktadır. Bu model, kendisine ulaşan bu istek üzerine görüntüde bulunan harfleri bölütledikten sonra sırasıyla tanımlamaktadır. Tanılamış olduğu harfleri dijital yazı şekline getirerek mobil uygulamaya iletmektedir. Bu sayede kullanıcı elinde bulunan yazıyı hızlı ve etkin bir şekilde dijital ortama aktarmış olur.

\section{2. İlgili Çalışmalar}

Bu kısımda, el yazısı tanıma işlemi yapan bazı çalışmalar incelenmektedir. Literatürde el yazısı tanıma işlemi gerçekleştiren birçok program ve yine bu konuyla ilgili gerçekleştirilmiş birçok araştırma ve çalışma bulunmaktadır. Bu bölümde bu çalışmalar incelenmektedir.

Gerçekleştirilen çalışmanın literatürdeki çalışmalara göre yeni yönleri bulunmaktadır. $\mathrm{Bu}$ yönlerden en önemlisi çalışmanın gerçekleştirildiği ortam olan mobil uygulama platformudur. Bu mobil uygulama platformu çoklu platform (hem iOS hem de Android işletim sistemlerinde çalışabilen) özelliği bulunan, Dart programlama dili ile Google'a ait olan Flutter platformunda gerçekleştirilmiştir. Çoklu platform özelliği olması daha fazla kullanıcının bu uygulamaya erişebilmesini sağlamıştır. Yazılım ürünlerinde en önemli faktörlerden biri olan sade ve anlaş1lır kod yazabilme Flutter ile mümkündür. Bu sayede çalışmadan faydalanmak isteyen yazılımcılar bu çalışmayı rahatlıkla kaynak kod olarak kullanabilir. Flutter'ın en bilinen özelliği ise diğer çoklu platform teknolojilerine göre çok daha hızlı çalışmasıdır. Bu sayede kullanıcıların daha kullanıcı dostu bir şekilde bu uygulamayı kullanabilmeleri sağlanmıştır.

Pençe ve Cetişli [3] el yazısı karakterlerini kapalı cebirsel eğrilerle modellemeyi ve sınıflandırmayı amaçlamıştır. El yazısıyla yazılan sayıların 8. dereceden cebirsel denklemleri elde edilerek öznitelik olarak denklem katsayıları kullanılmıştır. Elde edilen katsayıların değişmez olması için sadece ölçekleme ve ötelemeye göre normalize edilmişılerdir. Çalışmada, önerilen yöntemin Bayes ve yapay sinir ağları ile tanıma başarısı, MNIST el yazısı sayısal veri tabanı kullanılarak ölçülmüştür. Çalışmada elde edilen \%92,87'lik tanıma oranı henüz diğer yöntemlerle kıyaslanamaz ancak yöntem geliştirilerek her karakterin bir denklem ile ifade edilebileceği açıklanmıştır. Böylece karakterleri görüntü formatında saklamak yerine katsayılı olarak saklayarak daha az bellek kullanilabilir [3]. 
Salhou'nun araştırmasına [4] göre; Yapay Zeka araştırmaları, son yıllarda makine öğrenmesinin alt alanı olan Derin Öğrenme'ye odaklanmıştır. Bu yeni araştırma alanı gittikçe önem kazanmaktadır ve görüntü tanıma, görüntü sınıflandırma, konuşma tanıma gibi problemlerde iyi sonuçlar vermektedir. Bu çalışmada Derin Sinir Ağları (Deep Neural Network - DNN) veya Çok Katmanlı Algılayıcı (Multi-Layer Perceptron - MLP), Evrişimsel Sinir Ağı (Convolutional Neural Network - CNN) ve Uzun Kısa Süreli Bellek (Long Short Term Memory - LSTM) adı verilen Devirli Sinir Ağ̀ (Recurrent Neural Network - RNN) olmak üzere üç Derin Öğrenme algoritması kullanılarak MNIST, FASHION-MNIST, CIFAR-10 ve ARABIC veri setleri üzerinde el yazısı tanıma ve görüntü sınıflandırma işlemleri gerçekleştirilmiş, ilk aşamada modellerin sonuçları karşılaştırılmıştır. Daha sonra, kullanılan algoritmalar literatürde önerilen benzer modellerin sonuçları ile karşılaştırılmıştır. Deneysel kısımda kullanılan veri setlerine göre önerilen modellerin test verilerindeki doğruluk ve kayıp değerleri açısından sonuçları, Tensorboard ortamında optimum dönem (epoch) sayıları bazında modeller testleri tamamladığında davranışları grafiksel olarak gösterilmiştir. Modellerin karşılaştırılması için veri setlerine göre sütun grafikler çizildi. El yazısı ve görüntü sınıflandırmasında CNN modelinin en iyisi olduğu not edilmiştir. RNN ve CNN açısından aynı veri setini kullanan benzer çalışmalar karşılaştırıldığında, bu çalışmada oluşturulan modellerin daha iyi sonuçlar verdiği görülmüştür. Deneysel çalışmanın sonunda, RNN (LTSM) Cifar-10 veri seti dışındaki tüm modellerimizin doğruluk değerlerinin giderek arttığ 1 ve kayıp değerlerinin giderek azaldığı ortaya çıkmıştır [4].

Uğurlu vd.'nin araştırmasına [5] göre; el yazısı insanların sağlık durumunu, zihinsel sorunlarını, geçmiş yaşamlarını ve gizli yeteneklerini anlamamıza yardımcı olan kullanışlı bir araçtır. Bu araştırmada görüntü işleme, karakter tanıma teknikleri ve yapay sinir ağları bir arada kullanılarak el yazısı analizinin bilgi güvenliğindeki önemi ortaya konulmaya çalışılmıştır. El yazısı analizleri klasik yöntemlerle yapılsa da yüksek doğruluk ve zaman tasarrufu için bu yaklaşımların kullanılması büyük önem taşımaktadır. Taranan bir dijital görüntüden karakter tanıma sorunu, görüntü işleme, karakter tanıma ve yapay zeka alanlarında büyük ilgi görmektedir. Sayısallaştırılmış görüntü çeşitli işlemlerden geçirlmiştir. Bu işlemlerin amacı, daha sonraki aşamalar (dilimleme, özellik çıkarma ve karakter tanıma) için ihtiyaç duyulan verileri daha uygun hale getirmektir. Veriler uygun hale getirildikten sonra histogram eşitleme ve gürültü giderme gibi birçok görüntü işleme tekniği kullanılmıştır. Daha sonra yapay sinir ağları kullanılarak harf ve karakter tanıma işlemleri gerçekleştirilmiştir [5].

Lee ve Verma [6], el yazısı tanıma için çizim süreci üzerine bir araştırma yapmıştır. El yazısında bölütleme, yazının içindeki karakterleri elde etmek amacıyla uygulanan bir işlemdir. Bu zor bir işlemdir. Bu karakterler birbirine yakın, eğimli ve üst üste binmiş olabilirler. Bölütleme problemini çözmek için hibrit bölütleme stratejileri, anahtar bölütleme ve doğrulama ana hatlarıyla belirtilmiştir. Literatürdeki bölütleme tekniklerinin temel zayıflığg, sıralı bir değerlendirme sürecinde yüksek zincirleme riskleri getirmeleridir. Bu çalışmada, bu riski azaltan ve bölütleme doğruluğunu artıran yeni bir İkili Bölütleme Algoritması (BSA) önerilmiştir. İkili Bölütleme Algoritması, melez bir bölütleme tekniğidir. BSA ile literatürdeki diğer teknikler arasındaki temel fark, BSA'nın sırasız bir bölütleme stratejisinin olmasıdır. Önerilen algoritma, CEDAR veri tabanı kullanılarak değerlendirilmiştir ve deneylerin sonuçları umut vericidir [6].

Altwaijry ve Al-Turaiki, araştırmalarında [7] birçok uygulama için el yazısı tanımayı önemli bir 
bileşen olarak tanımlamaktadır. Latin dillerine ağırlık vermişlerdir. Literatürde Arap dilleri ile ilgili daha az sayıda çalışma olduğundan bahsetmişlerdir. Çalışmalarında, 591 katılımcı tarafindan yazılmış 47.434 karakterlik bir veri seti sunmuşlardır. Ayrıca, Evrişimli Sinir Ağlarına dayalı bir el yazısı tanıma modeli bulunmaktadır. Söz konusu model söz konusu veri seti ile eğitildiğinde sonuçların umut verici olduğu belirtilmektedir. Bu çalışma sonucunda \%97 doğruluk oranına ulaşıldığı açıklanmıştır [7].

Bunke vd. [8], Saklı Markov Modeli'ne (SMM) dayalı bir el yazısı tanıma yöntemi betimlemektedir. SMM'lerde kullanılan nitelikler, tanınacak kelimelerin iskelet grafiklerinin yaylarına dayanmaktadır. Bir kelimenin iskeletine, kenarları belirli bir sırayla çıkaran bir algoritma uygulanır. İskelet grafiğinden çıkarılan kenarların sırası göz önüne alındığında, her kenar 10 boyutlu bir nitelik vektörüne dönüştürülür. Nitelikler, dört referans çizgisine göre bir kenarın konumu, eğriliği ve dikkate alınan kenara ulaşan düğümlerin derecesi hakkında bilgileri temsil eder. Alfabenin her harfi doğrusal bir SMM ile temsil edilir. Sabit boyutlu bir sözlük verildiğinde, her sözlük kelimesi için bir SMM, kelimenin tek tek harflerini temsil eden SMM'lerin sırayla birleştirilmesiyle oluşturulur. SMM'lerin eğitimi Baum-Welch algoritması ile yapılırken tanıma için Viterbi algoritması kullanılmıştır. Her biri 150 kelimelik iki sözlük kullanan ortak yazarlarla yapılan deneylerde, kelime düzeyinde ortalama \%98'in üzerinde doğru tanıma oranı elde edilmiştir [8].

Bahlmann vd. [9] el yazısı tanıma amacıyla, dinamik zaman atlama ve destek vektör makinelerini birleştirerek yeni bir yaklaşım benimsediklerini vurgulamaktadır. Bu yaklaşım, yaygın Saklı Markov Modeli tekniklerine göre temel bir avantaja sahiptir. Üretici sınıf, koşullu yoğunluklar için bir model varsaymaz. Bunun yerine, sınıf sınırları oluşturarak ayrımcılık konusunu doğrudan ele alır ve bu nedenle modelleme varsayımlarına daha az duyarlıdır. Bu sayede, değişken boyutlu sıralı verilerle genel sınıflandırma sorunları çözülebilir. Bu bağlamda, önerilen yöntem, makul bir mesafe ölçüsü olan konuşma tanıma veya genom işleme gibi tüm sınıflandırma problemlerine doğrudan uygulanabilir. Bu yöntemle el yazısı verileri üzerinde deneyler yaparak HMM tabanlı bir yönteme yakın sonuçlar elde edilmiştir [9].

Balcı vd. [10], bir el yazısı metnini dijital bir forma çevirebilmek için kelimeleri teker teker tanıma yolunu seçmişlerdir. Bu görevi yerine getirmek için iki ana yaklaşım kullanılmıştır: kelimeleri doğrudan sinıflandırma ve karakter segmentasyonu. İlki için, kelimeleri doğru bir şekilde sınıflandırabilen bir Evrişimli Sinir Ağı (ESA) kullanılmıştır. İkincisinde, her karakter için sınırlayıcı kutular oluşturmak amacıyla evrişimli Uzun Kısa Süreli Bellek (UKSB) ağları kullanılmıştır. Daha sonra bölümlere ayrılmış karakterleri sınıflandırmak için bir ESA'ya geçirilmiş ve ardından sınıflandırma ve bölümleme sonuçlarına göre her bir kelime tanımaya çalışılmıştır [10].

Yang vd. [11], derin öğrenmeye dayalı yeni bir el yazısı metin tanıma algoritması sunmaktadır. Bir nesne algılama algoritmasına (Faster R-CNN) dayanan yöntem, sorunu incelemek için yeni bir boyut getirmiştir. Algoritma iki adımdan oluşmuştur: Birinci adım, Faster R-CNN'ye dayalı olarak el yazısı karakterinin ön işlenmesidir. İkincisi, Evrişimli Sinir Ağlarına dayalı karakter tanıma adımıdır. Test verilerine göre, bu yöntemin doğruluğu, geleneksel karakter tanımadan daha iyi olduğu öne sürülmüştür [11]. 
Albahli vd. [12] elle yazılmış sayı tanıma için mevcut tekniklerin, büyük ölçüde elle kodlanmış anahtar noktalara dayandığını ve önbilgi gerektirdiğini savunmuştur. Bu ön koşullarla verimli bir HDR ağı eğitmek karmaşık bir iştir. Son zamanlarda, sayı tanıma üzerine yapılan çalışmalar temel olarak derin öğrenme yaklaşımlarına odaklanmış ve dikkate değer sonuçlar sergilemiştir. Bununla birlikte, kişiden kişiye değişen yazı stilleri ve girdi örneğinde bulanıklık, bozulma, 1şık ve boyut farklılıklarının varlığı nedeniyle sayıların etkili bir şekilde algılanması ve sınıflandırılması hala zor bir iştir. Yazarlar, bu zorlukla başa çıkmak için, özelleştirilmiş daha hızlı bölgesel evrişimli sinir ağını (Faster-RCNN) tanıtan etkili ve verimli bir sayı tanıma sistemi sunmuştur. Bu yaklaşım üç ana adımdan oluşmaktadır. İlk olarak, ilgilenilen bölgeyi elde etmek için notlar yaratılır. Ardından, derin nitelikleri hesaplamak için DenseNet-41'in işin içine katıldığı gelişmiş bir Faster-RCNN kullanılır. Son olarak, regresör ve sınıflandırma katmanı, rakamları on sınıfa ayırmak için kullanılır. Önerilen yöntemin performansı, aydınlatma koşullarındaki değişiklikler, renklilik, rakamların şekli ve boyutu, bulanıklık ve gürültü etkilerinin oluşumu açısından çeşitlilik gösteren standart MNIST veritabanında analiz edilmiştir. Ayrıca, önerilen yöntemin etkinliğini kanıtlamak için bir çapraz veri seti senaryosu ile değerlendirilmiştir. Deneysel değerlendirmeler, yaklaşımın diğer yöntemlerden daha etkin olduğunu ve sayıları doğru bir şekilde tespit edip sınıflandırabildiğini göstermiştir [12].

\section{Sistem Mimarisi}

Bu bölümde, geliştirilen systemin mimarisi anlatılmaktadır. Sistem, Şekil 1'de görüldüğü gibi istemci sunucu mimarisinde geliştirilmiştir. Mobil uygulama (istemci) kısmı Flutter çerçevesi kullanılarak Dart programlama dili ile yazılmıştır.

Derin öğrenme modeli olarak, [13-16] kaynaklarında bahsedilen model kullanılmıştır. Kullanılan derin öğrenme modelinin detaylı özellikleri için bu kaynaklara başvurulmalıdır. Derin öğrenme modeli, Python dilinde Tensorflow kütüphanesi kullanılarak gerçekleştirilmiştir. Bu derin öğrenme modeli belirli veri seti kullanılarak eğitilmektedir ve harfleri belirli başarı oranlarında tanıyabilmektedir.

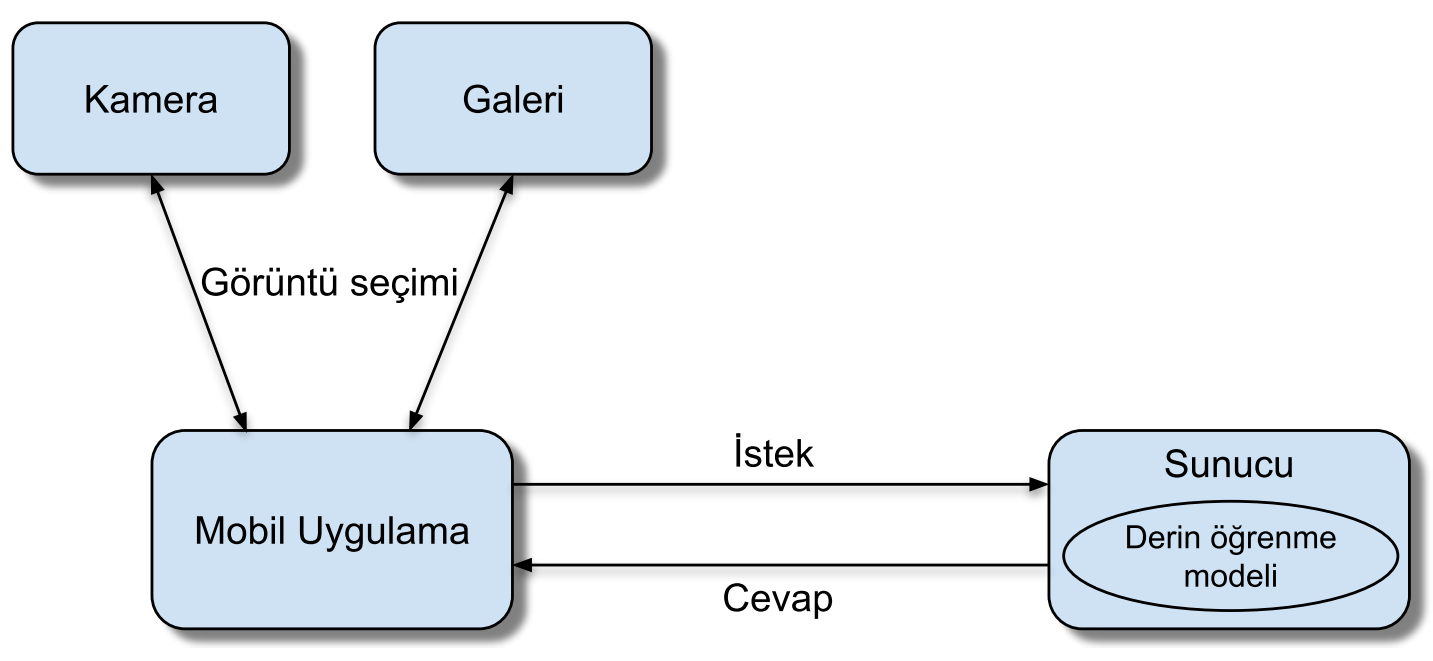

Şekil 1. Sistem mimarisi 
İstemci tarafını oluşturan mobil uygulama ise Flutter çerçevesi kullanılarak geliştirilmiştir. Mobil uygulamada kullanıcının karşısına Şekil 2'de görüldüğü gibi 3 adet buton çıkmaktadır. Bu butonlardan birincisi kameraya erişim ve kameradan çekilen fotoğrafin seçilmesi işlemini gerçekleştirmektedir. $\mathrm{Bu}$ amaçla kullanıcıdan izin almak gerekmektedir. $\mathrm{Bu}$ işlevi kullanarak kullanıcı kamerayı kullanarak anlık olarak fotoğraf çekerek elde ettiği görüntüyü mobil uygulamada kullanabilmektedir.

İkinci buton ise galeriden görüntü seçilmesini sağlamaktadır. Bu seçim işlemi için kullanıcıdan izin alınması gerekmektedir. Bu sayede kullanıcı sorunsuz bir şekilde bu butona dokunduğunda uygulama galeri kısmına gitmektedir ve kullanıcı buradan bir görüntü seçebilmektedir.

Kullanıcının seçmiş olduğu görüntü (galeri veya kamera farkı olmadan) seçimin hemen sonrasında Şekil 3'te görüldüğü gibi butonların üst kısmında görünür. Böylece kullanıcı seçmiş olduğu görüntü ile ilgili bir şüphe yaşamaz. Son buton olarak dönüştürme işlemi gerçekleştiren buton mevcuttur. Kullanıcı bu butona dokunarak seçmiş olduğu görüntüyü sunucuda bulunan derin öğrenme modeline gönderir. Görüntüde tanınan metin Şekil 3 'te görüldüğü gibi kullanıcıya gösterilir.

\section{$1: 18 \simeq 0$ \\ Upload Image Demo}

\section{4}

\section{$\bullet$}

\section{ㅁ}

Şekil 2. Uygulamanın başlangıç ekranı

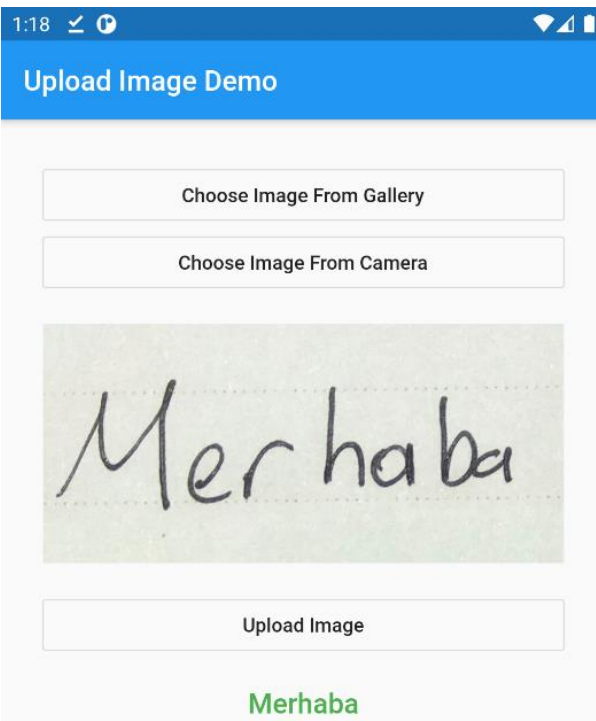

4

Şekil 3. Örnek çıtıtı 
Sunucu tarafta ise bir Derin Öğrenme modeli bulunmaktadır ve istemcilerden gelen isteklere yanıt verilmektedir. Sunucu ortamı Python programlama dili ve Flask çerçevesi kullanılarak oluşturulmuştur. Sunucuya bir POST isteği geldiği zaman, görüntü Derin Öğrenme modeline girdi olarak verilir ve çıktı istemci tarafına geri gönderilir. Bu aşamadaki deneysel çalışmalar ve testler Postman uygulama ortamında gerçekleştirilmiştir.

\section{Değerlendirme}

Derin Öğrenme modeli daha sonra yazılan yazıları tanıyabilecek şekilde geliştirilerek test edilmiştir. Bu kelimelerin belirli hatalar içerdiği gözlemlenmiştir. Test verileri ve alınan çıktılar Şekil 4'te görülmektedir. Çıktılar incelendiğinde bazı karakterler de hatalar olduğu görülmektedir. $\mathrm{Bu}$ karakter hatalarına rağmen genelde kelimeler insan tarafından anlaşılabilirdir. Kelimelerin ait olduğu dilde sözlük kullanılarak başarım arttırılabilir.

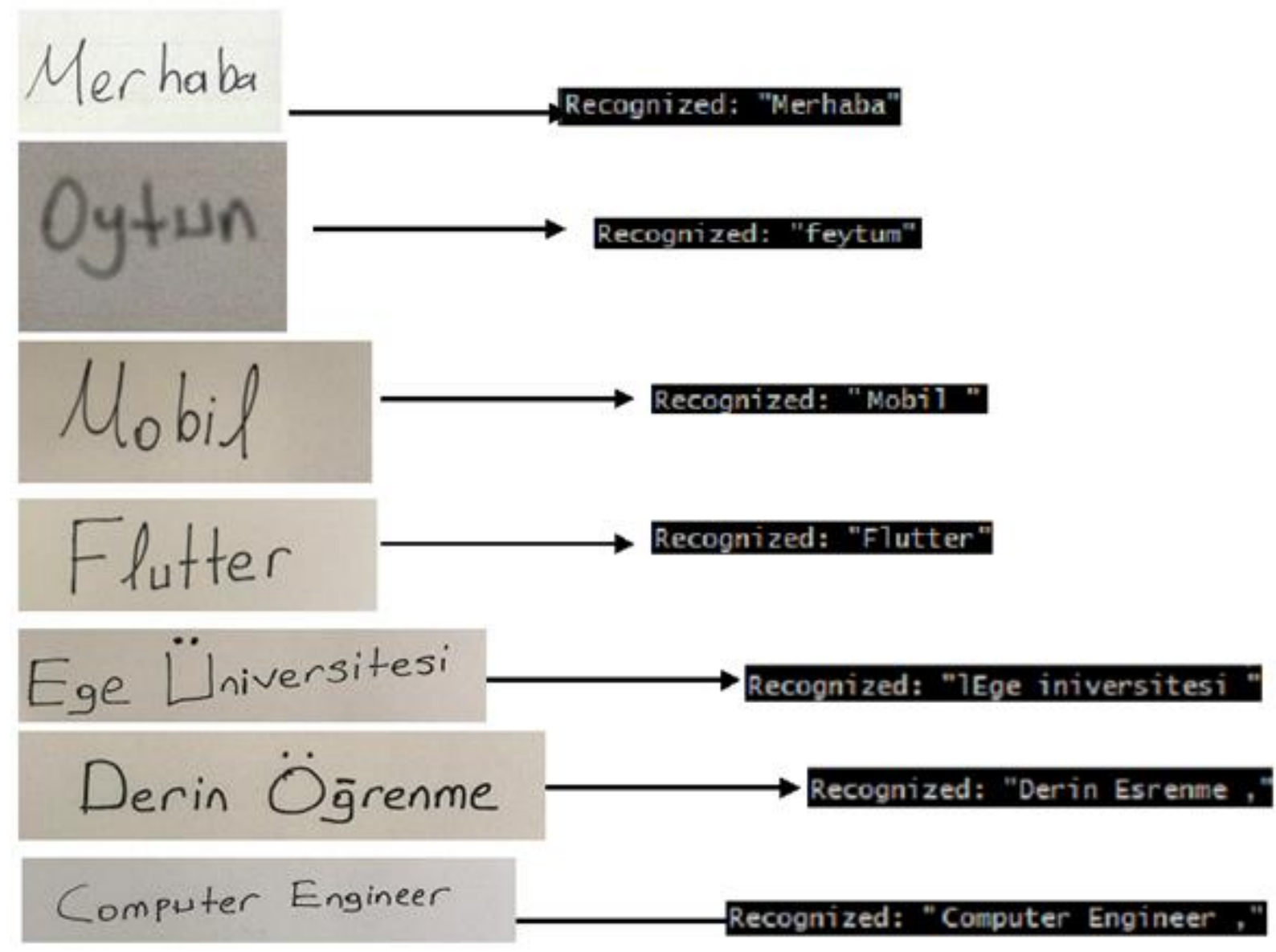

Şekil 4. Kullanılan test verisi ile alınan çıktılar 


\section{Sonuç}

Günümüzde Yapay Zeka alanında yaşanan gelişmeler ve hemen herkesin sahip olduğu akıllı telefonlar sayesinde günlük hayatımızda veya iş hayatımızda yaşadığımız çeşitli zorluklar daha kolay aşılabilir hale gelmiştir. Teknolojinin insanların hayatına bu şekilde kolaylaştırıcı olarak dokunabilmesi geleceğe daha umut dolu ve motive bir şekilde bakılabilmesini sağlamıştır. Böylece yazılım, yapay zeka gibi teknolojilere hakim olmayan kişiler bile teknoloji ve teknolojiyle ilgili bahsetmiş olduğumuz alanlara katkı sağlamaktadır.

$\mathrm{Bu}$ çalışmada yapay zeka kullanan bir mobil uygulama anlatılmaktadır. Bu uygulamada kullanıcılar akıllı telefonları sayesinde ellerinde bulunan yazılı kaynakları dijital ortama son derece pratik bir şekilde taşıyabilmektedir. Görüntülere, akıllı telefonlarının galerisinden veya anlık olarak mobil uygulamadan kameraya erişerek ulaşabilmektedirler. Ulaşmış oldukları görüntüde mevcut olan yazıları tek bir butona dokunarak dijital bir forma dönüştürebilmektedirler.

Kullanılan model henüz sadece belirli görüntüler üzerinde tanımlama yaparak faaliyet gösterebilecek durumdadır. İleri çalışma olarak, Derin Öğrenme modelinin optimize edilerek ve sözlük kullanılarak daha doğru sonuçlar elde edilmesi amaçlanmaktadır. Bu sayede doğruluk oranı yüksek sonuçlar alınabilecektir.

\section{Kaynaklar}

[1] Uzun E, Çă̆ıltay K. Çevrimiçi El Yazısı Tanıma Sistemi Olan Graffiti'nin Kullanılabilirlik Açısından Değerlendirilmesi. Uluslararası Teknolojik Bilimler Dergisi 2012;4(1):46-57.

[2] Hughes NC. How Handwriting Recognition Technology Improves Productivity On-the-Go. Inc.com; 2016. Accessed 2021/08/14. https://www.inc.com/neil-c-hughes/why-its-time-totake-handwriting-recognition-technology-seriously.html

[3] Pençe İ, Cetişli B. El Yazı Karakterlerinin Kapalı Cebirsel Eğrilerle Modellenmesi ve Sinıflandirılması. Sigma Journal of Engineering and Natural Sciences 2013;5:1-7.

[4] Salouhou A. El Yazısı Karakter Tanıma ve Resim Sınıflandırmada Derin Öğrenme Yaklaşımları. Yüksek Lisans Tezi. Fatih Sultan Mehmet Vakıf Üniversitesi; 2019.

[5] Uğurlu B, Kaçan K, Türkyılmaz İ. Bilgi Güvenliğinde El Yazısı. Akademik Bilişim '10 2010. p. 409-14.

[6] Lee H, Verma B. Binary segmentation algorithm for English cursive handwriting recognition. Pattern Recognition 2012;45(4):1306-17. doi:https://doi.org/10.1016/j.patcog.2011.09.015 
[7] Altwaijry N, Al-Turaiki I. Arabic handwriting recognition system using convolutional neural network. Neural Computing and Applications 2021;33(7):2249-61. doi:https://doi.org/10.1007/s00521-020-05070-8

[8] Bunke H, Roth M, Schukat-Talamazzini EG. Off-line cursive handwriting recognition using hidden markov models. Pattern Recognition 1995;28(9):1399-413. doi:https://doi.org/10.1016/0031-3203(95)00013-P

[9] Bahlmann C, Haasdonk B, Burkhardt H. Online handwriting recognition with support vector machines - a kernel approach. Proceedings of the 8th International Workshop on Frontiers in Handwriting Recognition. 2002. p. 49-54.

[10] Balci B, Saadati D, Shiferaw D. Handwritten Text Recognition using Deep Learning. CS231n: Convolutional Neural Networks for Visual Recognition. Course Project Report: Stanford Uni.; 2017.

[11] Yang J, Ren P, Kong X. Handwriting Text Recognition Based on Faster R-CNN. 2019 Chinese Automation Congress (CAC). 2019. p. 2450-4.

[12] Albahli S, Nawaz M, Javed A, Irtaza A. An improved faster-RCNN model for handwritten character recognition. Arabian Journal for Science and Engineering 2021.doi:https://doi.org/10.1007/s13369-021-05471-4

[13] Matcha ACN. How to easily do Handwriting Recognition using Deep Learning. 2021. Accessed 2021/08/14. https://nanonets.com/blog/handwritten-character-recognition/

[14] Scheidl H. Build a Handwritten Text Recognition System using TensorFlow. 2018. Accessed 2021/08/14. https://towardsdatascience.com/build-a-handwritten-text-recognition-systemusing-tensorflow-2326a3487cd5

[15] Scheidl H. Handwritten Text Recognition with TensorFlow. 2021. Accessed 2021/08/14. https://github.com/githubharald/SimpleHTR

[16] Scheidl H, Fiel S, Sablatnig R. Word Beam Search: A Connectionist Temporal Classification Decoding Algorithm. Proceedings of the 16th International Conference on Frontiers in Handwriting Recognition (ICFHR). 2018. p. 253-8. 